\title{
Casi toda la narrativa reciente sobre la Guerra Civil (2014-2018) y una breve reflexión sobre algunos conceptos clave
}

Grupo de Investigación Bibliográfica de AMESDE. 2016. 2014. Un año de narrativa sobre la Guerra Civil y el franquismo. Bibliografía comentada. Prólogo de José Manuel Pérez Carrera. Madrid: AMESDE/ Edaf. 2017. 2015. Un año de narrativa sobre la Guerra de España y el franquismo. Bibliografía comentada. Prólogo de José Manuel Pérez Carrera. Madrid: AMESDE/Edaf.

- 2018. 2016. Un año de narrativa sobre la Guerra Civil y el franquismo. Bibliografía comentada. Presentación de José Manuel Pérez Carrera. Madrid: AMESDE/Edaf.

. 2018. 2017. Un año de narrativa sobre la Guerra Civil y el franquismo. Bibliografía comentada. Presentación de José Manuel Pérez Carrera. Madrid: AMESDE/Edaf. - 2019. Repertorio bibliográfico sobre la narrativa en catalán de la Guerra de España (1936-1939), el exilio y el franquismo. Prólogo de José Manuel Pérez Carrera. Madrid: AMESDE.

. 2020. 2018. Un año de narrativa sobre la Guerra Civil y el franquismo. Bibliografía comentada. Presentación de José Manuel Pérez Carrera. Madrid: AMESDE.

FERNANDO VALLS

Universidad Autónoma de Barcelona (España)

https://orcid.org/0000-0001-5304-1138

doi: https://dx.doi.org/10.7238/dd.voig.394363

En el año 2004 se creó en Madrid la Asociación de la Memoria Social y Democrática (AMESDE) con el objetivo de "promover, estudiar y difundir el conocimiento del pasado", además de alcanzar, siguiendo a Blas de Otero, «la belleza siempre que no esté en contraposición a la verdad, es decir, a la justicia», según se lee en la presentación del primer volumen de la colección que trataremos, a cargo de Jaime Ruiz, presidente de dicho organismo. 
La entrega inicial, que se ocupa de los libros de 2014, tuvo su origen en el taller de lectura «Memoria de la Guerra Civil y del franquismo en la literatura», que dirigió el profesor José Manuel Pérez Carrera, coordinador de los seis libros publicados hasta ahora, trabajo para el que ha contado con la ayuda de un equipo de colaboradores, entre los que destacaría, si nos atenemos a sus publicaciones, a Julián Moreiro y Maryse Bertrand de Muñoz, fallecidos en 2016 y 2019, respectivamente. Esta ambiciosa empresa cuenta con algunos antecedentes, como el libro de María José Montes (La guerra española en la creación literaria. Ensayo bibliográfico, 1970), el de Carlos Fernández Santander (Bibliografía de la novela de la Guerra Civil española. 1936-1986, 1986) y, sobre todo, los cuatro volúmenes publicados por la citada profesora canadiense Maryse Bertrand entre 1982 (La Guerra Civil española en la novela. Bibliografía comentada) y 1994 (La novela europea y americana y la Guerra Civil española).

Los textos que ahora nos ocupan incluyen fichas sobre cada uno de los libros abordados, en las que aparecen una descripción bibliográfica, la indicación del periodo histórico tratado (preguerra, guerra o postguerra), el argumento y los componentes esenciales de las narraciones, e incluso hallamos a veces una valoración, algunos datos mínimos sobre el autor y unas referencias bibliográficas de las críticas que haya generado, aunque en este último apartado se observan carencias. ${ }^{1}$ Otros libros se solventan con un comentario más sucinto. Sea como fuere, en el caso de las antologías y de los libros de cuentos debería señalarse siempre qué piezas en concreto tratan de nuestra guerra.

En 2014 la producción narrativa sobre la Guerra Civil fue notable en comparación con otros años. Según Pérez Carrera, dicho aumento se debió al cambio político que se produjo con la victoria electoral de Aznar en 1996, que permaneció en el poder hasta el 2004. Más discutible me

1 Así, por ejemplo, de Los pacientes del doctor García, de Almudena Grandes, se citan las reseñas de Daniel Arjona, J. Ernesto Ayala-Dip, J. A. Masoliver Ródenas y J. A. Juristo, además de la entrevista de N. Azancot. Sin embargo, también debería haberse dejado constancia de las reseñas de Eva Díaz Pérez (Mercurio) y Fernando Valls (Turia), y de las entrevistas y crónicas de Clara Morales y Pablo Bonet (ambas en infoLibre), Xavi Ayén (La Vanguardia), Guillem Andrés (El País), Anna Abella (El Periódico), Manuel Haro (en la web Llegir en cas d'incendi) y Suso Mourelo (L y más), pues todas ellas creo que están disponibles en la red. 
parece el hecho, que se repite una y otra vez, como si se tratara de una verdad establecida, aunque hayan surgido numerosas e importantes voces discrepantes, de que la Transición supusiera en su momento una especie de pacto de silencio a cambio de la reconciliación y del olvido del pasado. Si en el ámbito oficial pudo ser así, no lo fue en absoluto en el ámbito —digamos - ciudadano, social y privado, no menos importante, pues no faltaron entonces profesores, periódicos y revistas que nos informaran al respecto, ni programas de televisión, libros y fascículos que contaran qué fue el franquismo y las trágicas consecuencias que acarreó la Guerra Civil. E incluso un narrador de cierto mérito - aunque en sus novelas, que resultan reiterativas, le gusta regodearse en las efusiones sentimentaloides y se da a las bravatas-, ha llegado a sostener, refiriéndose al presente, que nadie puede obligarlo a que olvide. Pero la pregunta que me hago es quién podría olvidar hoy, y cómo. En estos temas suelen ir de la mano el desconocimiento, el fanatismo y la demagogia, excesos que ni un escritor ni tampoco un investigador pueden permitirse.

En el prólogo de este primer volumen, cuya pauta general siguen los restantes, se afirma que fue en 1938 y 1939 cuando se publicaron más novelas sobre la guerra, cincuenta y tres y cuarenta y ocho, respectivamente, mientras que entre 1940 y 1975 la media anual descendió de forma significativa a dieciocho títulos, y entre 1975 y 1997 apareció un libro menos. En cambio, a partir de 1997 y hasta 2014 la media de títulos se duplicó, llegando a treinta y nueve por año, hasta el punto de que en 2007 Isaac Rosa se lamentaba de tal proliferación en el título de uno de sus libros: ¡Otra maldita novela sobre la Guerra Civil! Quizás ese aumento fuera una manera de contestar a los revisionistas, aficionados a la historia, tales como Pío Moa (Los orígenes de la Guerra Civil española, 1999; El derrumbre de la Segunda República y la Guerra Civil, 2001; Los mitos de la Guerra Civil, 2003, y La Guerra Civil española, 1936-1939. Un análisis crítico, 2014) ${ }^{2}$ y César Vidal (Paracuellos Katyn. Un ensayo sobre el genocidio de la izquierda, 2005, y Checas de Madrid, 2007), cuyas obras habían aparecido unos años antes. Aunque ningún historiador sensato

2 Véase la respuesta de Alberto Reig Tapia (Anti Moa. La subversión neofranquista de la historia de España, Barcelona: Ediciones B, 2006). 
se las tomara en serio, la difusión que alcanzaron hizo mucho daño, confundiendo a lectores de ideología conservadora poco informados y con grandes tragaderas.

Esa interpretación sectaria que parecía haberse superado, veinte años después se pone de manifiesto de nuevo con las declaraciones de Ignacio Camuñas, exministro de la UCD y vicepresidente de VOX en 2014, aunque ya no forma parte de ese grupo. Camuñas, en unas jornadas celebradas en Ávila, «Concordia, Constitución y patriotismo», organizadas por la Fundación Concordia y Libertad, que preside Adolfo Suárez Illana, ${ }^{3}$ afirmó que la República fue la responsable de la Guerra Civil y que no hubo golpe de Estado en 1936. Dicha declaración contó con el silencio cómplice de Pablo Casado, secretario general del PP, presente en el acto, quien un poco antes había comentado en el Congreso de los Diputados que «la Guerra Civil fue un enfrentamiento entre los que querían la democracia sin ley y los que querían la ley sin democracia».4 A este lo rectificaba su compañero de partido y presidente de la Xunta de Galicia, Alberto Núñez Feijóo, al apostillar que la guerra surgió de un golpe de Estado, opinión que ha compartido Cayetana Álvarez de Toledo, del mismo partido, y Begoña Villacís, de Ciudadanos: «Sí hubo un golpe de Estado y también una dictadura». Ada Colau, la actual alcaldesa de Barcelona, en un pleno del Ayuntamiento celebrado el 23 de julio de 2021, tras criticar a Pablo Casado afirmó que «un golpe de Estado fascista liderado por Franco fue lo que provocó la Guerra Civil». También lo han rebatido historiadores tan importantes como Ángel Viñas — «¿Qué concordia puede desarrollar y elaborar un partido que se niega a aceptar la historia y prefiere su pequeñita historia de simples creencias?»—, citado por Màrius Carol, Enrique Moradiellos o Julián Casanova. Todo este cruce de declaraciones se enmarca en un contexto en el que el Gobierno PSOE-Podemos intenta

3 No parece casualidad que en 1996 el periodista Abel Hernández publicara un libro, Adolfo Suárez. Fue posible la concordia, en la editorial Espasa Calpe, en cuyo título aparecía el mismo sustantivo.

4 En un artículo reciente («18 de julio de 1936. Palabra, pólvora y cimientos», El País, 18 jul. 2021, 13), la historiadora Pilar Mera le contestaba en los siguientes términos: «Decir que la Guerra Civil fue un enfrentamiento entre quienes querían la democracia sin ley y quienes querían la ley sin democracia es apostar por la grandilocuencia y el juego de palabras de significado vacío. Pero ese vacío iguala a quienes se sublevaron contra la democracia y contra la ley, con aquellos que ejercían el poder de manera legítima al amparo de las normas donde se cimentaba el sistema democrático vigente». 
aprobar una nueva ley de la (el artículo es imprescindible) memoria democrática, que no cuenta ni con el apoyo del PP, ni de VOX, ni de Podemos ni de los independentistas catalanes, aunque por razones diferentes, $\mathrm{y}$ que sustituirá la de 2007, promulgada durante el gobierno de José Luis Rodríguez Zapatero. ${ }^{5}$

Tanto Gonzalo Sobejano como la profesora Bertrand de Muñoz han propuesto distintas categorías para diferenciar estos libros. El primero ha distinguido entre los novelistas observadores (aquellos cuya experiencia bélica es pasiva), militantes (los que intervinieron en la lucha o son portavoces de una ideología) o intérpretes (todos los que indagan en el significado de los sucesos y que surgieron primero entre los exiliados republicanos). Con el paso del tiempo acabaron predominando las obras pertenecientes al último grupo. Por su parte, la profesora canadiense habla de novelas de la guerra vivida, de la guerra presentida, de la recordada y de novelas de la guerra referida, siendo así que acabaría por imponerse este último grupo. ${ }^{6}$

Comenta Pérez Carrera que, a partir de 2001, con la publicación de Soldados de Salamina, aparece en España un nuevo modelo de novela, aquella en la que la contienda se presenta como objeto de investigación,

5 Cf. los textos de E. García de Blas - «Feijóo enmienda a Casado sus palabras sobre la Guerra Civil» (El País, 7 jul. 2021) —, Natalia Junquera — “La represión franquista es una falsedad”» (El País, 16 jul. 2018, 20; El País, 9 jul. 2021, 19), sobre la Fundación Francisco Franco, y «Śnchez impulsa la ley de memoria en plena ola de revisionismo histórico» (El País, 21 jul. 2021, 18-19) - Javier Casqueiro — «Casado amenaza a Sánchez con Bruselas si cambia la elección del Poder Judicial» y «Camuñas y el golpe del 36, Arias y Rutte» (El País, 20 jul. 2021, 13), un artículo y una entrevista con Pablo de Greiff- y E. Tasca y E. García de Blas - «El PP recibe críticas por el acto de Casado con el exministro Camuñas» (El País, 21 jul. 2021, 18-19). Véase también el editorial de La Vanguardia «La dificultad de cerrar heridas» (21 jul. 2021), dos artículos de Màrius Carol («Negacionistas de la historia») y FrancescMarc Álvaro («Nacho, la noche y el fiscal»), ambos publicados el 22 de julio de 2021, y una crónica de Raúl Montilla («El tono se eleva y avinagra el debate político»), con la afirmación de Colau, los cuatro aparecidos en dicho periódico de Barcelona.

6 En una nota de la introducción al volumen publicado en 2019, Pérez Carrera aduce otros marbetes, como «novelas de la guerra investigada», «nueva novela histórica», el más general «autoficción», o el propuesto por José Martínez Rubio (Las formas de la verdad. Investigación, docuficción y memoria en la novela hispánica, 2015), «novelas de investigación de escritor». Los miembros de AMESDE proponen el concepto de "novelas de la memoria histórica". Excepto el de "autoficción", utilizado con frecuencia, aunque muy cuestionado, el resto no ha gozado de la aceptación de los investigadores. En el caso de las denominadas "novelas de la memoria histórica", los tres conceptos me parece que chocan entre sí y se repelen. 
resultando en algunos casos hasta detectivesca. Pero a la vez constata que este tipo de historias van perdiendo interés fuera de España. En esencia, la mayoría de las novelas utiliza el siguiente esquema, según se dice en el citado prólogo: un joven encuentra en la actualidad, por azar, un documento u objeto desconocido que le llama la atención y lo investiga, a veces con la ayuda de un periodista o de un investigador privado, de modo que sus pesquisas lo conducen a algún acontecimiento enigmático ocurrido durante la guerra o como consecuencia de esta. A menudo, parece interesar más el desarrollo de la investigación y la aclaración del misterio que la trágica historia de fondo.

Sea como fuere, en 2014 aparecieron sesenta y siete narraciones, entre ellas varias novelas de interés, como son La soledad de los perdidos, de Luis Mateo Díez; Tierra violenta, de Luciano G. Egido; En la pell de l'altre, de Maria Barbal; Todo lejos, de Alfons Cervera; Las tres bodas de Manolita, de Almudena Grandes; El impostor, de Javier Cercas; No encuentro mi cara en el espejo, de Fulgencio Argüelles; Los extraños, de Vicente Valero; La bella cubana, de José María Conget, y La larga noche, de Javier Mije.

En 2015 se amplia el número hasta setenta y cinco narraciones, una cifra que no se había alcanzado en ningún otro año. Llama la atención que a las razones conocidas de este auge se sume otra que hoy sabemos falsa (que España era el segundo país con más fosas comunes cerradas tras Camboya), pues utiliza de manera incorrecta una información que proporcionó Miguel Ángel Rodríguez Arias, repetida por el juez Baltasar Garzón y difundida por Irene Montero y Pablo Iglesias, sin atender bien a los detalles y al contexto que proporcionaba Rodríguez Arias. Si nos atenemos a la calidad literaria de las narraciones, lo único que importa al fin y a la postre, el 2015 no resultó tan fecundo, y solo podemos destacar Donde no estás, de Gustavo Martín Garzo; La sega, de Martí Domínguez; El faro y la noche, de Selena Millares; La vieja, de Federico de Arce, considerado un «relato breve y estremecedor» (pág. 131), y El botín, de Miguel SánchezOstiz, aunque esta última obra se recrea demasiado en el tremendismo de la historia que cuenta. Por lo que se refiere a los estudios sobre nuestra materia - los comentarios no están firmados-, creo que se exagera el interés del libro de David Becerra Mayor, La Guerra Civil como moda literaria, en mi opinión demasiado zhanovista, por lo que tiene de 
simplista y sesgado, mientras que se valora en cambio de forma adecuada el de Gregorio Morán, El cura y los mandarines, del que se comenta: «La arbitrariedad y el desconocimiento de aspectos fundamentales de la cultura literaria de la época por parte del autor malogran una obra que, sin embargo, ofrece análisis parciales de gran interés. Si bien, de ninguna manera, se puede considerar este libro como la referencia a la vida cultural y literaria española durante el franquismo y la Transición» (p. 169 y 171). Recuérdese, al respecto, la atrevida tesis sostenida por Becerra Mayor, según la cual el auge de las novelas sobre la Guerra Civil era consecuencia de la posmodernidad, del auge del liberalismo. Pero quizá debiéramos preguntarnos si en la mayoría de los casos no se trataría más bien de un afán por explotar un filón que parecía interesar a los lectores menos exigentes, vinculado al auge de la novela histórica y a las políticas de la memoria, y valorar cuántas de estas narraciones destacan por su calidad literaria, así como cuántas cuentan algo significativo sobre la guerra que todavía no supiéramos, o la enfocaban siquiera de una forma diferente.

En la presentación del volumen relativo a los libros publicados a lo largo de 2016, Pérez Carrera comenta la discusión mantenida entre los miembros del grupo de investigación, a los que se sumó en esa fecha la profesora Maryse Bertrand, sobre qué concepto utilizar: si el de "Guerra de España”, que usó Azaña y en general los defensores de la legalidad republicana, o el clásico de "Guerra Civil”, empleado por los historiadores de derechas y de izquierdas y, según Pérez Carrera, por los partidarios de «esa renovada entelequia de la tercera España, equidistantes ante el horror de los unos y los otros»: «Unamuno sería el primer ejemplo de una larga serie de nombres que continúa con Chaves Nogales y Ortega, y termina con Pérez Reverte y Trapiello» (p. 11 y 12). Pero a estos nombres, que no parecen despreciables y que deberían haberle hecho pensar a Pérez Carrera antes de emitir juicios tan taxativos, habría que sumárseles otros, como los de Salvador de Madariaga, el periodista Gaziel y el editor José o Josep Vergés, que estaban en la misma onda. El de la "tercera España” es un concepto discutible, tanto como el de las “dos Españas” (en 1937, León Felipe había afirmado en una conferencia: «Hay dos Españas y siempre ha habido dos Españas, y nosotros, los revolucionarios españoles, queremos que no haya 
más que una, una sola»), si bien para cuestionarlo o defenderlo habría que emplear argumentos más sólidos y mejor fundamentados.?

El caso es que, tras utilizar el marbete de "Guerra de España" en 2015, finalmente se decantaron por el de "Guerra Civil" para facilitar la búsqueda bibliográfica, aunque el primero les pareciera más correcto. Por una vez, creíamos que se había acabado imponiendo el sentido común, pero en el volumen publicado en 2019 aparece de nuevo el de "Guerra de España", mientras que en el tomo publicado en 2020 volvemos a encontrar el de "Guerra Civil".

Los vencedores en la guerra, a través de la censura y de las consignas de obligatorio cumplimiento en la prensa, impusieron diversas denominaciones (sobre todo las de "Guerra de Liberación" o "Cruzada"), impidiendo que se utilizara la de "Guerra Civil", hasta el punto de que en novelas de Concha Espina (Retaguardia, 1937), Carmen Laforet (La mujer nueva, 1955), Ricardo Fernández la Reguera (Bienaventurados los que aman, 1957) y Torcuato Luca de Tena (Edad prohibida, 1958) los censores la tachan. ${ }^{8}$ Tanto en España como en Francia, hasta los años sesenta, se utilizó - ¿siempre? - la expresión "Guerra de España”. En 1968, la sección correspondiente del Ministerio - ¿de Información y Turismo? se denominaba “de la Guerra de España”. Fueron los corresponsales de guerra anglosajones, ${ }^{9}$ y luego el historiador Hugh Thomas (The Spanish Civil War) y el periodista Burnett Bolloten (The Grand Camouflage: The Communist Conspiracy in the Spanish Civil War, traducido al castellano

7 Véase Paul Preston, Las tres Españas del 36, Barcelona: Plaza \& Janés, 1998; Javier Ruiz Portella, ed., La Guerra Civil: ¿dos o tres Españas?, Barcelona: Áltera, 1999, y Alberto Reig Tapia y Josep Sánchez Cervelló, ed., La Guerra Civil española, 8 o años después. Un conflicto internacional y una fractura cultural, Madrid: Tecnos, 2019, 148 y 357-371. El historiador Fernando del Rey Reguillo, autor del libro Retaguardia roja. Violencia y revolución en la Guerra Civil española (2019), con el que obtuvo el Premio Nacional de Historia, en una entrevista que le hizo Luis Alemany para el diario El Mundo (13 oct. 2019), comentaba que «eso de las dos Españas fue un invento de los sectarios» y que «si acaso hubo cuatro Españas: una revolucionaria, otra contrarrevolucionaria, una liberal y otra que intentaba sobrevivir». En suma, que, al paso que vamos, acabará habiendo tantas Españas como españoles, si no más.

8 Cf. Fernando Larraz, Letricidio español. Censura y novela durante el franquismo, Gijón: Trea, 2014, 107 y 108, y en su estela Javier Sánchez Zapatero, Arde Madrid. Narrativa y Guerra Civil, Sevilla: Renacimiento, 2020, 160 .

9 Véase Carlos García Santa Cecilia, Corresponsales en la Guerra de España, 1936-1939, Madrid: Instituto Cervantes / Fundación Pablo Iglesias, 2006, y Paul Preston, Idealistas bajo las balas: corresponsales extranjeros en la Guerra de España, Barcelona: Debate, 2007. 
por Luis de Caralt como El gran engaño. Las izquierdas y su lucha por el poder en la zona republicana) quienes empezaron a denominarla "Guerra Civil" en sus libros de 1961.

A este respecto, permítanme una breve digresión. No existen muchos trabajos - me refiero sobre todo a libros, aunque sin olvidar del todo los folletos (por ejemplo, los de Luis Araquistáin o Luis Miguel de Zulátegui) — y artículos que utilicen en su título el concepto de "Guerra de España", o sus posibles variantes "guerra española" o "guerra de los españoles". Entre ellos se encuentra la recopilación de Marc Hanrez, que recoge veintitrés colaboraciones, en tres de las cuales (las de Claude Pichois, Georges Piroué, director de las Éditions Denoël, y Serge Salaün) hallamos también dicha expresión. A ellos podrían sumarse también los títulos de la bibliografía de este mismo volumen, al cuidado de Maryse Bertrand, que incluye, del campo de la historia y de la ficción, un artículo de Mariano Baquero Goyanes — «La guerra española en nuestra novela» (Ateneo, núm. 3, 1952)—, historiador de la literatura, Aldo Garosci -Gli intellettuali nella guerra spagnola (Milán: Feltrinelli, 1959) —, Vicente Marrero - La guerra española y el 'trust' de cerebros (Madrid: Punta Europa, 1961) - y Rafael Calvo Serer - La literatura universal sobre la Guerra de España (Madrid: Ateneo, 1962). Asimismo, también menciona estudios de Mijaíl Koltsov —Diario de la Guerra de España (París: Ruedo Ibérico, 1963)—, Ricardo de la Cierva -Cien libros básicos sobre la Guerra de España (Madrid: Publicaciones Españolas, 1966)—, Eduardo Comín Colomer -Cuadernos bibliográficos de la Guerra de España (Madrid: Universidad Complutense, 1966-1969)—, Tomás Salvador - La Guerra de España en sus fotografías (Barcelona: Marte, 1966) - y Stephen Cartwright - pseudónimo del crítico e historiador Joaquim Molas, autor de la edición de la antología Poesia catalana de la Guerra d'Espanya (1936-1939) i de la resistència, (París: Edicions Catalanes de Paris, 1969). En el campo de la ficción, Bertrand hace referencia a Manuel Andújar - El vencido. Novela sobre la Guerra de España (México: Almendros y Cía., 1949) - y a Max Aub —Últimos cuentos de la Guerra de España (Caracas: Monte Ávila, 1969). Y no sé si podemos incluir en este cómputo dos antologías, una seleccionada por el gran filólogo Antonio Rodríguez Moñino y Emilio Prados — Romancero general de la Guerra de España (Madrid: Ediciones Españolas, 1937)—y otra prologada por Rafael 
Alberti - Romancero general de la guerra española (Buenos Aires: Losada, 1944), reeditado en 2006 por Visor Libros.

En el libro de Julián Casanova República y Guerra Civil (Barcelona: Crítica / Marcial Pons, 2014), las expresiones alternativas a "Guerra Civil" solo aparecen en tres ocasiones. También se usan en los libros de María Luisa Rodríguez Aisa - El cardenal Gomá y la Guerra de España. Aspectos de la gestión pública del Primado, 1936-1939 (Madrid: CSIC, 1981)—, de Walther L. Bernecker —Guerra en España. 1936-1939 (Madrid: Síntesis, 1996) y de Ángel Bahamonde y Javier Cervera —Así terminó la Guerra de España (Madrid: Marcial Pons, 1999). En la bibliografía que cierra el libro de Enrique Moradiellos Historia mínima de la Guerra Civil española (Madrid: Turner / El Colegio de México, 2016), el marbete aparece en el título de otras tres obras: en una suya del 2012 - La Guerra de España. 1936-1939. Estudios y controversias (Barcelona: RBA, 2012) - , en otra coordinada por Santos Juliá -República y Guerra de España. 1931-1939 (Madrid: Espasa Calpe, 2006) - y en otra de Carlos Engel -Estrategia y táctica en la Guerra de España, 1936-1939 (Madrid: Almena, 2008). ${ }^{10}$ En cambio, en el Diccionario biobibliográfico de los escritores, editoriales y revistas del exilio republicano de 1939 (Sevilla: Renacimiento, 2016), al cuidado de Manuel Aznar Soler y José-Ramón López García, dada su extensión, encontramos numerosas referencias, que recojo en un apéndice final, y casi todas remiten a obras publicadas fuera de España por los exiliados republicanos. En las múltiples bibliografías del volumen coordinado por Alberto Reig Tapia y Josep Sánchez Cervelló, ya citado, encontramos estas expresiones en los libros de David Jorge - Inseguridad colectiva. La Sociedad de Naciones, la Guerra de España y el fin de la paz mundial (Valencia: Tirant lo Blanch, 2016)—, Paul Preston —Idealistas bajo las balas. Corresponsales extranjeros en la Guerra de España, ya citado-, en los coordinados por Edward Malefakis - La Guerra de España, 1936-1939 (Taurus, 1996) - y Jordi Canal y Vincent Duclert — La guerre d'Espagne. Un conflict qui a façonné l'Europe (Armand Colin, 2016). Asimismo, esta expresión la usan dos republicanos muy notables: Manuel Azaña - La

10 Téngase en cuenta que para no repetir las referencias solo cito títulos y autores la primera vez que aparecen en alguno de estos volúmenes. 
velada en Benicarló. Diálogo de la Guerra de España (Buenos Aires: Losada, 1939) - y el general Vicente Rojo - España heroica. Diez bocetos de la guerra española (Buenos Aires: AméricaLee, 1942), reeditado en 1961 por Ediciones Era y en 1975 por Ariel. Por otro lado, en el libro colectivo coordinado por Ángel Viñas - En el combate por la historia. La República, la Guerra civil, el franquismo (Barcelona: Pasado \& Presente, 2020), en el que cada capítulo lleva su bibliografía correspondiente, nos encontramos con los libros de Juan Avilés Farré - Las grandes potencias ante la Guerra de España (Madrid: Arco-Libro, 1998) - y seis referencias más, citadas ya todas ellas, a excepción de tres libros del general Vicente Rojo que hasta ahora no habíamos tenido en cuenta: ¡Alerta los pueblos! Estudio político-militar del período final de la guerra española (Barcelona: Ariel, 1974), Así fue la defensa de Madrid. Aportación a la historia de la Guerra de España (Madrid: Comunidad de Madrid, 1987) y Historia de la Guerra Civil española (Barcelona: RBA, 2010). Por último, en el estudio reciente de Pilar Mera Costas (2021), aunque no incluye una bibliografía general, sí podemos espigar en las notas finales los libros que utiliza, y solo en uno, de Fernando Díaz-Plaja (La Guerra de España en sus documentos, 1986), encontramos dichos marbetes. ${ }^{11}$

Esta modesta búsqueda no es concluyente, ni mucho menos, pero sí creo que nos permite deducir, aunque sea provisionalmente, que el término "Guerra Civil" ha acabado imponiéndose definitivamente y que el de "Guerra de España” se ha utilizado poco en las últimas décadas. Las excepciones resultan variopintas, pues lo usaron los historiadores franquistas (Eduardo Comín Colomer, Rafael Calvo Serer, Vicente Marrero y Ricardo de la Cierva), la mayoría de los exiliados republicanos (Azaña,

11 Cf. Maryse Bertrand de Muñoz, «Bibliografía selectiva de la Guerra Civil española», dentro Marc Hanrez, ed., Los escritores y la Guerra de España, Barcelona: Libros de Monte Ávila, 1976, 325368; Julián Casanova, Historia de España, vol. 8, República y Guerra Civil, Barcelona: Crítica y Marcial Pons, 2014; Enrique Moradiellos, Historia mínima de la Guerra Civil española, Madrid/México: Turner / El Colegio de México, 2016, 293-298; Manuel Aznar Soler y José-Ramón López García, ed., Diccionario biobibliográfico de los escritores, editoriales y revistas del exilio republicano de 1939, Sevilla: Renacimiento, 2016, y Alberto Reig Tapia y Josep Sánchez Cervelló, op. cit. (la bibliografía aparece al final de cada uno de los 24 capítulos). Véase también Ángel Viñas, ed., En el combate por la historia. La República, la Guerra Civil, el franquismo, Barcelona: Pasado \& Presente, 2020, y Pilar Mera Costas, 18 de julio de 1936. El día que empezó la Guerra Civil, Madrid: Taurus, 2021, 209-221. 
el general Vicente Rojo, Luis Araquistáin, Francisco Largo Caballero, Julián Zugazagoitia, Indalecio Prieto, Ángel Ossorio y Gallardo, Pablo de Azcárate e Ignacio Hidalgo de Cisneros, y, entre los escritores, Max Aub, Emilio Prados, Carlota O’Neill o Manuel Andújar, aunque en otras ocasiones también se valen del término "Guerra Civil") ${ }^{12}$ e historiadores y escritores de izquierdas (Arthur London, Aldo Garosci, Malefakis o Preston), aunque otros parecen valerse de él como sinónimo de "Guerra Civil", pues encontramos ambos en sus libros, como ocurre - por ejemplo- en los casos de Santos Juliá, Paul Preston ${ }^{13}$ y Enrique Moradiellos y, en el libro coordinado por Santa Bañares (1988), incluso en el mismo título aparecen ambos conceptos como sinónimos. Por último, tras una rápida búsqueda en internet, observo que cuatro historiadores clásicos en lo que se refiere a esta materia - Hugh Thomas, Manuel Tuñón de Lara, Gabriel Jackson y Stanley G. Payne - utilizaron siempre la expresión “Guerra Civil”. En suma, este término tardó en empezar a utilizarse, en el interior por razones obvias y en el exilio porque se prefirió otro concepto, como hemos visto. Por otra parte, a los que eran conscientes de la internacionalización de la guerra - a brigadistas como Arthur London (1978), para empezar - no les parecía adecuado, por engañoso. Los géneros en los que se utiliza son variados, aunque predominan los libros de historia y los testimonios, sin que falten las ficciones, los reportajes novelados, como el libro de Romualdo Sánchez Granados, los diarios, como el de Emilio Prados, o las bibliografías. Resultaría de sumo interés que los miembros de AMESDE o de esta revista que me acoge hicieran una encuesta entre los especialistas en la historia de la guerra de 1936-1939 o en la literatura que ha producido sobre el uso de estos conceptos ("Guerra Civil”, "Guerra de España”, "guerra española” y "guerra de los españoles"), sobre si significan lo mismo para ellos y por qué utilizan uno u otro marbete.

El caso es que, regresando al centro de mi argumentación, en 2016 el número de narraciones había descendido a cincuenta y cinco, cantidad que

12 Por ejemplo, Manuel Andújar («Narrativa sobre la Guerra Civil en la España peregrina y en la España permanecida») dentro Manfred Engelbert y Javier García de María, ed., La Guerra Civil española. Medio siglo después, Frankfurt: Vervuert, 1990, 123-135.

13 Preston ha utilizado ambos, aunque en las últimas décadas se ha decantado por el de "Guerra Civil". 
no resulta desdeñable, aunque sea inferior a la de los dos años anteriores. Entre ellas, «destacan la pujanza y calidad de las narraciones escritas en catalán» (p. 13) y, por lo que se refiere a la temática, sigue prevaleciendo lo que denominan «la guerra investigada». O sea, «en aquellas novelas situadas en el presente, una circunstancia o un descubrimiento fortuito hacen retroceder la acción al pasado de la guerra para aclarar el sentido de esa revelación» (p. 13), según hemos visto.

Del tomo en cuestión, yo destacaría los siguientes títulos y autores: Otro mundo, de Alfons Cervera; La inocencia lesionada, de Juan Antonio Masoliver Ródenas, del que Pilar de Mena afirma que «es una joya» (pág. 52); Falcó, de Arturo Pérez Reverte, que Maryse Bertrand critica por equidistante y por insistir en los aspectos más negativos de la contienda, aunque habría que preguntarse si hubo algunos positivos; No cantaremos en tierra de extraños, de Ernesto Pérez Zúñiga; El grupo. 1964-1974, de Ana Puértolas, que podría leerse en paralelo con La larga marcha (1996), de Rafael Chirbes; O encargo do señor Castelao, de Luís Rei Núñez; Un extraño viajero, de Manuel Rico; La hora de despertarnos juntos, de Kirmen Uribe, cuya versión original es en lengua vasca; Soles negros, de Ignacio del Valle; El oído absoluto, de Manuel Longares; La ciutat de ningú, de Antoni Vidal Ferrando, sobre el que Pérez Carrera opina que se trata «de un libro muy bien escrito, de una estructura narrativa perfecta y de una prosa muy brillante y eficaz, en la que todo se insinúa y sugiere con gran sutileza» $\mathrm{y}$ que, en definitiva, «reclama su pronta traducción al castellano» (p. 10o). Y, aunque no conozco la obra, me ha llamado la atención la novela de Mercè Foradada Estimades Zambrano, que se ocupa de la peripecia vital de las hermanas Araceli y María Zambrano. En suma, el balance es positivo, aunque no me parece que literariamente destaque en especial ninguno de los libros citados.

En 2017, según comenta en la presentación Pérez Carrera, descendió el número de narraciones publicadas, aunque sobresalga de nuevo la pujanza en cantidad y calidad de las escritas en catalán. Y por lo que se refiere a los temas, llama la atención las numerosas novelas que se dedican a recrear la existencia de personajes históricos. Destacaría Retorn, de Carles Casajuana, sobre el regreso a Cataluña de Josep Carner; El monarca de las sombras, de Javier Cercas (en la bibliografía se citan dos atrabiliarias reseñas de 
Francisco Espinosa Maestre y Sebastiaan Faber, quienes parecen desconocer lo que es una novela y lo que supone la ficción, junto a otras tres mucho más atinadas de José Carlos Mainer, José María Pozuelo Yvancos y Domingo Ródenas de Moya, a quien debemos una edición modélica de Soldados de Salamina que ha dejado en evidencia las numerosas tonterías que se han escrito sobre esta novela); El hoy es malo, pero el mañana es nuestro, de Salvador Compán, que Pérez Carrera define como «una novela compleja, muy bien estructurada, de gran riqueza verbal y preciosismo estilítico» (pág. 36); Los pacientes del doctor García, de Almudena Grandes, obra que obtuvo el Premio Nacional de Narrativa en 2018 y el Jean-Monnet de literatura europea en 2020; Perros que duermen, de Juan Madrid; Eva, de Arturo Pérez-Reverte; Banderas en la niebla, de Javier Reverte, en la cual uno de sus protagonistas es el torero El Algabeño, a quien Chaves Nogales le había dedicado el cuento «La gesta de los caballistas» en A sangre y fuego; Alguien bajo los párpados, de Cristina Sánchez Andrade; La sorra vermella, de J. N. Santaeulàlia; Recordarán tu nombre, de Lorenzo Silva; Historia ilustrada del mundo, de Anelio Rodríguez Concepción, uno de esos narradores a los que le hemos prestado mucha menos atención de la que merece, y La hija del comunista, de Aroa Moreno Durán, novela a la que se le dedica un comentario creo que poco atinado.

En el 2018 se publican sesenta y cinco títulos. ${ }^{14}$ Pérez Carrera afirma que ninguna de las novelas publicadas ese año «arroja una visión especialmente novedosa del tema» (p. 14). Sin embargo, me ha llamado la atención la novela histórica — así se define a través de su subtítulo-, de Carlos Blanco Aguinaga, Viajes de ida, uno de los componentes de la segunda generación de escritores del exilio republicano y prestigioso historiador de la literatura española e hispanoamericana. A ellas podrían sumársele obras de Alfons Cervera (La noche que los Beatles llegaron a Barcelona), Jordi Coca (Els ulls dels homes mentiders), Joan-Lluís Lluís (Jo soc aquell que va matar Franco), Ignacio Martínez de Pisón (Filek: el estafador que

14 Véase la crónica de M. M., «En España se publican cada año 70 novelas sobre la Guerra Civil» (El País, 20 oct. 2018), con motivo de un congreso celebrado en Salamanca, en el que participaron, entre otros, José Manuel Pérez Carrera, María José Turrión y Ana Rodríguez Fischer. 
engañó a Franco), Arturo Pérez-Reverte (Sabotaje), Ernesto Pérez Zúñiga (Escarcha) y Jordi Soler (Usos rudimentarios de la selva, libro de relatos).

Quiero detenerme, por último, en el repertorio sobre la narrativa en catalán, cuyo antecedente principal es el artículo de Helena Mesalles, ${ }^{15}$ para el cual los miembros de AMESDE han contado con la colaboración de Ignasi Riera, narrador, ensayista y poeta, antiguo editor de Laia, ahora afincado en Madrid. Pérez Carrera destaca en la introducción el gran número de autores y de obras, 249 y 430 , respectivamente, y comenta que buena parte de ellas están escritas en primera persona, pues muchas tienen su origen en testimonios vividos. En las tres últimas décadas, entre el año 1991 y 2018, aumentó el número de títulos hasta un total de 251, cuando entre 1939 y 1990 solo se publicaron 179. Con respecto a los motivos de la escasez de obras durante el franquismo, es obvio que se debe a la censura, cuyas injerencias no fueron compensadas por la producción en el exilio, sobre todo en México y Chile.

Los autores aparecen primero por orden alfabético y luego se ordenan los libros siguiendo la fecha de publicación. Así, sobresalen las obras de Joaquim Amat-Piniella (su K. L. Reich, de 1963 y en edición completa en 2001, fue traducida al castellano por un joven Baltasar Porcel en 1963), Maria Barbal (Pedra de tartera, de 1985, la tradujo Ana María Moix en 1995), Agustí Bartra (la historia de su novela testimonio, Crist de 200.000 braços, con ediciones en catalán y castellano, merecería un comentario aparte), ${ }^{16}$ Xavier Benguerel (Els fugitius, de 1956, aunque en su versión definitiva de 1969 se denominó Els vençuts, título que sigue en 1972 la versión en castellano), ${ }^{17}$ Blai Bonet, Jaume Cabré, Pere Calders, Maria Aurèlia Capmany, Jordi Coca, Andreu Martín, J. F. Mira, Terenci Moix, Jesús Moncada, Víctor Mora, Anna Murià, Teresa Pàmies, Baltasar Porcel, Valentí Puig, Joan Puig i Ferrater, Carme Riera, Viçenc Riera Llorca (Tots

15 Véase «Bibliografia de la memòria i ficció de la Guerra Civil espanyola en la literatura catalana», dentro Institut d'Estudis Ilerdencs, Literatura de la Guerra Civil. Memòria i ficció, Lleida: Edicions de l'IEI, 2002, 261-353.

16 En una nota a Xabola (México, 1943), novela de Bartra, se dice que obtuvo en 1944 el Premio Fastenrath de la Real Academia Española, algo imposible teniendo en cuenta que su autor era un exiliado republicano que escribía en catalán. Ese año, el citado premio se le concedió a Dámaso Alonso (La poesía de San Juan de la Cruz) y a Juan Antonio Zunzunegui (¡Ay..., estos hijos!).

17 Recuérdese que I vinti (Los vencidos), de 1953, fue también el título de una película de Antonioni. 
tres surten per l'Ozama, de 1946, fue muy criticada por Vicente Llorens, quien también estuvo exiliado en la República Dominicana), Miquel Àngel Riera, Mercè Rodoreda (La plaça del Diamant, de 1962; pero algunas de sus obras restantes fueron traducidas al castellano por Ana María Moix, Clara Janés y Pere Gimferrer), Montserrat Roig, Joan Sales (Incerta glòria, de 1956 y con una edición definitiva en 1971, traducida al castellano por Carlos Pujol), Ramon Solsona, Emili Teixidor, Enric Valor, Guillem Viladot, Llorenç Villalonga y la antología Contes de guerra i revolució (1982), al cuidado de la profesora Maria Campillo.

Estos volúmenes no solo se limitan a la literatura, aunque la presencia de esta sea mayoritaria, sino que también aparecen referencias a los cómics, pomposamente llamados ahora "novelas gráficas" — destacaría la versión de Los girasoles ciegos (Zaragoza: Edelvives, 2017), de Alberto Méndez, ilustrado por Gianluigi Toccafondo e incluido en la colección «Contempla»-, y a la bibliografía que ha generado el tema que nos ocupa. Y puesto que se reproducen las cubiertas de muchos de estos libros, podrían estudiarse y sacar conclusiones, en la línea del meritorio trabajo publicado por Juan Vila. ${ }^{18}$

Entre tantas virtudes, en el libro aparecen unos pocos errores en los nombres citados (por ejemplo, José debe ser Josep; Néspalo, en el volumen de 2018, es Néspolo (p. 52 y 56); Ródenas Mayoy es Ródenas de Moya, mientras que Guido, en el título de 2020, es Guinda (p. 98 y 146). La bibliografía que se aduce de cada uno de los libros — reseñas casi siempreresulta incompleta, según ya hemos advertido. Y a veces se ocupan de relatos que poco o nada tienen que ver con la Guerra Civil, como ocurre - por ejemplo- en los casos de Rayos (2016), de Miqui Otero, o de Hotel Lutecia (2017), de Empar Fernández. Sorprende que no aparezca ninguna referencia al libro de Andrés Trapiello (Las armas y las letras. Literatura y Guerra Civil. 1936-1939), con ediciones corregidas y aumentadas en los años 1994, 2002, 2010 y 2019, quizás el más importante publicado nunca sobre la materia. De la misma manera, resulta llamativo que existan varios

18 Véase «Traces et témoignage: le paradigme photographique du roman de la mémoire», dentro J. F. Carcelen, ed., Témoignage et fiction dans l'Espagne contemporaine, Montpellier/Mercuès: Presses Universitaires de la Méditerranée, 2012, 147-162. 
estudios en los que se analiza la novela sobre la guerra y ninguno que se ocupe del cuento, ni siquiera en forma de artículo panorámico, aunque en estos volúmenes sí se tiene en cuenta este género.

Al final, si pensamos en la historia literaria, al fin y al cabo estamos ocupándonos de ficciones: lo que sobre todo debería importarnos es si han aparecido narraciones de calidad que tengan como tema la Guerra Civil. La respuesta es que sí. Para los estudiosos de esta materia y de la narrativa de postguerra, estos que tratamos son ya libros imprescindibles y un claro ejemplo de las ventajas que puede llevar consigo trabajar en equipo. Esperamos con sumo interés los próximos volúmenes. ${ }^{19}$

19 Quiero darle las gracias al editor Gonzalo Pontón y a su hijo, el profesor Gonzalo Pontón Gijón, compañero de departamento, viejos y queridos amigos, y también a Olívia Gassol Bellet, paciente y sabia editora. 


\section{Apéndice}

Álvarez, Santiago. ¿1988? Cincuentenario de la guerra española. Homenaje a las Brigadas Internacionales. Prólogo de Dolores Ibárruri. S. 1.: s. e.

Araquistaín, Luis. 1939. El comunismo y la Guerra de España. Más dos cartas de Stalin a Largo Caballero. Folleto. Carmaux Tarn: Imprimérie des Travailleurs Réunis.

Arias Arias, Antonio. 1995. "Arde el cielo": memorias de un piloto de caza en la Guerra de España (1936-1939) y en la guerra patria de la URSS (1941-1945). Edición de José María Bravo. Silla: Delgado Romero.

Azaña, Manuel. Obras completas. 1966-1968. México: Oasis, 4 vol. [Uno de los apartados del tercer volumen se titula «La Guerra de España y su significado»].

. Obras completas. 1990. Madrid: Giner. [Uno de los apartados se titula «La Guerra de España y su significado»].

—.1986. Causas de la Guerra de España. Prólogo de Gabriel Jackson. Barcelona: Crítica.

- 1986. Causas de la Guerra de España. Barcelona: Grijalbo Mondadori.

- 2011. Causas de la Guerra de España. Colección «Biblioteca de la República». Barcelona: Diario Público.

- 2014. Escritos sobre la guerra en España. Barcelona: Crítica. [Incluye Los españoles en guerra y Causas de la Guerra de España].

- 2020. Causas de la Guerra de España. Prólogo de Gabriel Jackson. Barcelona: Booket.

Azcárate, Pablo de. 1957. La intervención nazi-fascista en la Guerra de España. S. 1.: s. e. ${ }^{20}$

Ballester, Carme. 1938. La Guerra de España en el plano internacional. Barcelona: Tierra y Libertad.

Bazal, Luis. 1966. jAy de los vencidos! Testimonio de la Guerra de España (1936-1939). Toulouse: autoedición.

Blasco Garzón, Manuel, ed. 1939. España heroica. Selección de los mejores poemas de la Guerra de España (1936-1939). Toulouse: Teatro del Pueblo.

Etchebéhère, Mika. 1976. Mi guerra de España. Barcelona: Plaza \& Janés.

Cierva, Ricardo de la, ed. 1968. Bibliografía general sobre la Guerra de España (19361939) y sus antecedentes históricos. Fuentes para la historia contemporánea de España. Barcelona: Ariel.

Cimorra, Clemente, ed. 1942. «Síntesis gráfica de la Guerra de España». Número extraordinario, Pensamiento español 9 (enero). [Revista bonaerense publicada entre 1941 y 1944].

Ciutat, Francisco. 1978. Relatos y reflexiones sobre la Guerra de España. Madrid: Forma. Cuevas, E. 1940. Recuerdos de la Guerra de España. Montauban: Impr. G. Forestié. Gamir, Mariano. 1939. De mis memorias. Guerra de España,1936-1939. París: Librería Española.

20 No he logrado saber quién lo editó. 
García Maroto, Gabriel, ed. 1937. Los dibujantes en la Guerra de España. Madrid/ Valencia: Ediciones Españolas.

García Pradas, José. 1939. La traición de Stalin. Cómo terminó la Guerra de España. Prólogo de Marcelino García. Nueva York: Cultura Proletaria.

Guarner, Vicente. 1975. Cataluña en la Guerra de España, 1936-1939. Madrid: Gregorio del Toro.

Hidalgo de Cisneros, Ignacio. 1964. Memorias. La República y la Guerra de España. París: Librairie du Globe.

Largo Caballero, Francisco. 1985. Escritos de la República: notas históricas de la Guerra de España. Madrid: Fundación Pablo Iglesias.

Llarch, Joan. 1976. Cipriano Mera: un anarquista en la Guerra de España. Barcelona: Euros.

London, Arthur. 1978. Se levantaron antes del alba. Memoria de un combatiente checo de las Brigadas Internacionales en la Guerra de España. Barcelona: Península.

Malefakis, Edward, coord. 1986. La Guerra de España, 1936-1939. Barcelona: Círculo de Lectores / El País.

O’Neill, Carlota. 1951. Una mujer en la Guerra de España. Caracas.

—.1964. Una mexicana en la Guerra de España. México: La Prensa.

1979. Una mujer en la Guerra de España. Madrid: Turner.

2003. Una mujer en la Guerra de España. Prólogo de Rafael Torres. Madrid: Oberon.

- 2005. Una mujer en la Guerra de España. Barcelona: RBA.

Ossorio y Gallardo, Ángel. 1942. La Guerra de España y los católicos. Buenos Aires: Publicaciones del Patronato Hispano-Argentino de Cultura.

Palacio Atard, Vicente, ed. 1967. Cuadernos bibliográficos de la Guerra de España. 19361939. Madrid: Universidad de Madrid, 3 vol.

Paz, Abel. 2005. La Guerra de España: paradigma de una revolución. Las treinta horas de Barcelona (julio del 36). Barcelona: Flor del Viento.

Prados, Emilio. S. f. Diario íntimo de un poeta en la guerra de España. S. 1.: s. e..1

Prieto, Indalecio. 1953. Entresijos de la Guerra de España. México: PSOE/UGT.

Rodríguez Moñino, Antonio, y Emilio Prados, ed. 1937. Romancero general de la Guerra de España. Madrid/Valencia: Ediciones Españolas.

Rojo, Vicente. 1967. Así fue la defensa de Madrid. Aproximación a la historia de la Guerra de España (1936-1939). México: Era.

—.1987. Así fue la defensa de Madrid. Aproximación a la historia de la Guerra de España (1936-1939). Madrid: Comunidad de Madrid.

Romero Solano, L. 1947. Vísperas de la Guerra de España. México: El Libro Perfecto.

Salaün, Serge, ed. 1971. Romancero de la Guerra de España. Vol. 1: Romancero libertario. París: Ruedo Ibérico.

21 Fue destruido por su autor en Banyuls (Girona) cuando abandonaba España. Lo conocemos solo por referencias. 
Salaün, Serge. 1982. Romancero de la Guerra de España. Vol. 3: Romancero de la tierra. Barcelona: Ruedo Ibérico.

-1985. La poesía de la Guerra de España. Madrid: Castalia.

Sánchez Granados, Romualdo. 1944. 98 horas (Escenas de la Guerra de España). Reportaje novelado. México: Gráficas Panamericana.

Santa Bañares, Àngels, ed. 1988. Literatura y Guerra Civil: influencia de la Guerra de España en las letras francesas e hispánicas. Barcelona: Universidad de Barcelona.

Suero Roca, María Teresa. 1981. Militares republicanos de la Guerra de España. Barcelona: Península.

Tarazona, Francisco. 1958. Sangre en el cielo. La aviación republicana en la Guerra de España. México: Costa-Amic, 1958.

Varios autores. 1941. Para un castillo de poemas. Poesía a la Guerra de España. Prólogo de Rafael Alberti. Buenos Aires: Columba.

Zugazagoitia, Julián. 1940. Historia de la Guerra de España. Buenos Aires: La Vanguardia. — 1968. Historia de la Guerra de España. Presentación de Roberto Mesa. París: Librería Española, 2 vol.

—.1977. Historia de la Guerra de España. Prólogo de Francisco Bustelo. Barcelona: Crítica.

-1978. Historia de la Guerra de España. Barcelona: Ediciones Éxito, 2 vol.

—. 2001. Historia de la Guerra de España. Prólogo de Santos Juliá. Barcelona: Tusquets.

Zulátegui, Luis Miguel de. 1937. La verdad sobre la Guerra de España. Folleto. S. 1.: s. e. _.1937. Más sobre la Guerra de España. Folleto. S. 1.: s. e. 